\title{
Correction to: A meaning-centered spiritual care training program for hospice palliative care teams in South Korea: development and preliminary evaluation
}

Kyung-Ah Kang ${ }^{1}$, Shin-Jeong Kim²*, Do-Bong Kim³ ${ }^{3}$ Myung-Hee Park ${ }^{4}$ Soo-Jin Yoon ${ }^{5}$, Sung-Eun Choi ${ }^{6}$, Young-Sim Choi ${ }^{7}$ and Su-Jin $\mathrm{Koh}^{8}$

Correction to: BMC Palliative Care 20, 30 (2021)

https://doi.org/10.1186/s12904-021-00718-1

Following publication of the original article [1], the authors reported that the Figures were not included in the published version.

The correct Figs. 1 and 2 and its captions have been included in this correction, and the original article has been corrected.

\footnotetext{
Author details

${ }^{1}$ College of Nursing, Sahmyook University, Seoul, Republic of Korea. ${ }^{2}$ School of Nursing, Hallym University, 39 Hallymdaehak-gil, Chuncheon, Gangwon-do 24252, Republic of Korea. ${ }^{3}$ Holistic Healing Institute of Sam Medical Center, Gunpo, Republic of Korea. ${ }^{4}$ Hospice \& Palliative Center, Seoul St. Mary's Hospital, Seoul, Republic of Korea. ${ }^{5}$ Dongbaek St. Luke Hospice, Gyeonggi-do, Republic of Korea. ${ }^{6}$ Hospice Care Center of the Regional Cancer Center, Chungnam University Hospital, Daejeon, Republic of Korea. ${ }^{7}$ Department of Nursing, Chungnam National University Hospital, Daejeon, Republic of Korea. ${ }^{8}$ Department of Hematology and Oncology, Ulsan University Hospital, University of Ulsan College of Medicine, Ulsan, Republic of Korea.
}

Published online: 11 May 2021

\section{Reference}

1. Kang KA, Kim SJ, Kim DB, Park MH, Yoon SJ, Choi SE, et al. A meaningcentered spiritual care training program for hospice palliative care teams in South Korea: development and preliminary evaluation. BMC Palliat Care. 2021;20(1):30. https://doi.org/10.1186/s12904-021-00718-1.

The original article can be found online at https://doi.org/10.1186/s12904 021-00718-1.

* Correspondence: ksj@hallym.ac.kr

${ }^{2}$ School of Nursing, Hallym University, 39 Hallymdaehak-gil, Chuncheon, Gangwon-do 24252, Republic of Korea

Full list of author information is available at the end of the article

(c) The Author(s). 2021 Open Access This article is licensed under a Creative Commons Attribution 4.0 International License, which permits use, sharing, adaptation, distribution and reproduction in any medium or format, as long as you give appropriate credit to the original author(s) and the source, provide a link to the Creative Commons licence, and indicate if changes were made. The images or other third party material in this article are included in the article's Creative Commons licence, unless indicated otherwise in a credit line to the material. If material is not included in the article's Creative Commons licence and your intended use is not permitted by statutory regulation or exceeds the permitted use, you will need to obtain permission directly from the copyright holder. To view a copy of this licence, visit http://creativecommons.org/licenses/by/4.0/ The Creative Commons Public Domain Dedication waiver (http://creativecommons.org/publicdomain/zero/1.0/) applies to the data made available in this article, unless otherwise stated in a credit line to the data. 

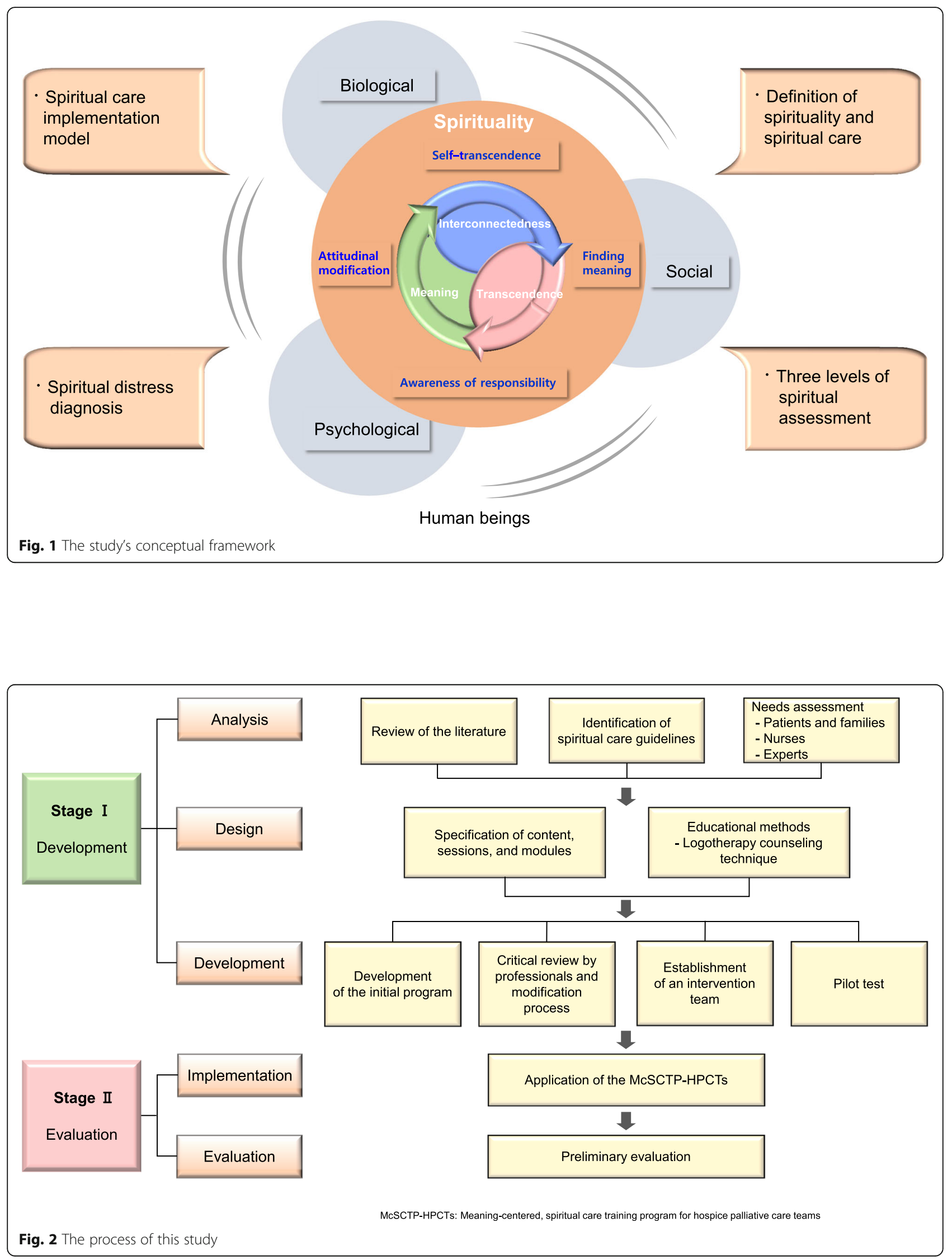